\title{
Methylenetetrahydrofolate Reductase Gene Germ-Line C677T and A1298C SNPs are Associated with Colorectal Cancer Risk in the Turkish Population
}

\author{
Filiz Ozen ${ }^{1}$, Metin Sen ${ }^{2}$, Ozturk Ozdemir ${ }^{1,3 *}$
}

\begin{abstract}
Colorectal cancer (CRC) is the third most common cause of death due to cancer in the worldwide and the incidence is also increasing in Turkey. Our present aim was to investigate any association between germ-line methylenetetrahydrofolate reductase $(M T H F R)$ C677T and A1298C polymorphisms and CRC risk in Turkey. A total of 86 CRC cases and 212 control individuals of the same ethnicity were included in the current study. Peripheral blood-DNA samples were used for genotyping by StripAssay technique, based on the reversehybridization principle and real-time PCR methods. Results were compared in Pearson Chi-square and multiple logistic regression models. The MTHFR 677TT (homozygous) genotype was found in $20.9 \%$ and the $T$ allele frequency 4.2-fold increased in CRC when compared with the control group.The second SNP MTHFR 1298CC (homozygous) genotype was found in $\mathbf{1 4 . 0 \%}$ and the $\mathrm{C}$ allele frequency 1.4-fold elevated in the CRC group. The current data suggest strong associations between both SNPs of germ-line $M T H F R$ 677 $\mathrm{C}>\mathrm{T}$ and $1298 \mathrm{~A}>\mathrm{C}$ genotypes and CRC susceptibility in the Turkish population. Now the results need to be confirmed with a larger sample size.
\end{abstract}

Keywords: MTHFR gene - SNPs - C677T and A1298C - colorectal cancer risk - Turkey

Asian Pac J Cancer Prev, 15 (18), 7731-7735

\section{Introduction}

Colorectal cancer is one of the most common types of cancer and the incidence varies and appears to be increasing in worldwide. Recent literature findings showed that the ethiological parameters such as; chromosomal rearrengements, point mutations, gene polymorphisms, environmental factors, lifestyles, and epigenetic alterations may cause to the CRCP (Fearon et al., 1990; de Kok et al., 2000; Parkin et al., 2002; Ulrich et al., 2002). The folate status in some cases was also reported in the CRC risk (Choi et al., 2000; Xu et al., 2004). The methylene tetrahydrofolate reductase (MTHFR) enzyme plays a crucial role in the folate metabolism that catalyzes the irreversible reaction of 5,10-methylene-tetrahydrofolate to 5-methyl tetrahydrofolate, which serves as a substrate for the remethylation of homocysteine to methionine, with the subsequent synthesis of $\mathrm{S}$ adenosylmethionine(Friedman et al., 1999; Parle et al., 2006; Slattery et al., 1999; Pardini et al., 2011). The substrate of MTHFR 5,10-methylenetetrahydrofolate, is also required for thymidine synthesis via thymidylate synthase, and indirectly for purine biosynthesis(Frosst et al., 1995; Weisberg et al., 1998). Decreasing the MTHFR enzyme function may cause to the global DNA hypomethylation due to lack of the intracelular methyl sources and initiates carcinogenesis process. (Blount et al., 1997; Stern et al., 2000; Fang et al., 2003).

Two common polymorphic SNPs were reported in exons 4 and 7 of MTHFR gene; one is defined in codon $677 \mathrm{C}<\mathrm{T}$ and the other one is in codon $1298 \mathrm{~A}<\mathrm{C}$. The first C677T SNP, positioned in exon 4 leading to an alanine to valine conversion Goyette et al., 1998). Individuals with homozygous MTHFR TT genotype have $30 \%$ and heterozygous carriers show $65 \%$ enzyme activity (Frosst et al., 1995). The TT genotype is also associated with higher plasma homocysteine and reduced plasma folate levels (Delougheryt et al., 1996; Schwartz et al., 1997). The second SNP in MTHFR gene, A1298C (rs1801131) in exon 7, lead to a glutamate to alanine substitution at codon 429 (E429A), (van der Put et al., 1998; Chen et al., 2002; Weisberg et al., 2002). This polymorphism lies in the C-terminal end of the enzyme, the S-adenosylmethionine regulatory domain, and may result in a decrease of $40 \%$ in enzyme activity of the variant genotype. Nevertheless, this variant has not associated either with a thermolabile enzyme or with alterations in the levels of homocysteine in the plasma (Weisberg et al., 2002). Both mutated MTHFR

${ }^{1}$ Department of Medical Genetics, ${ }^{2}$ Department of General Surgery, Faculty of Medicine, Cumhuriyet University, Sivas, ${ }^{3}$ Department of Medical Genetics, Faculty of Medicine, Canakkale Onsekiz Mart University, Canakkale,Turkey*For correspondence: ozdemir615@ yahoo.com 
gene profiles were reported in some cancer types (Izmirli et al., 2011; Izmirli et al., 2013). There are conflicting results that rangin from strong linkage and no association about MTHFR and CRC risk in different literature findings.

In the current case-control study, it was aimed to describe the effect of polymorphic germ-line folateassociated gene MTHFR markers (C677T and A1298C) in colorectal carcinoma in Turkish population.

\section{Materials and Methods}

Patients, clinical diagnosis and laboratory assessment In a total of 86 CRC patients; 70 colonal $(81.4 \%)$ and 16 rectal (18.6\%), 54 male (62.8\%), 32 female (37.2\%) and the mean age-min-max; $63.22 \pm 30.41$ (45-87) were included in the current report.The tumoural tissue samples were used for tissue specific proto-oncogene KRAS genotyping and epigenetic profiling (data not shown) and peripheral blood-EDTA samples from each patients were used for germ-line MTHFR gene profiling.The results belong to the germ-line mutation profiles for MTHFR gene were compared to the healthy individuals from the same ethnicity (Ozdemir et al., 2012). Peripheral blood-DNA samples were obtained during routine diagnosis from CRC patients in Cumhuriyet University Training and Research Hospital by the collaboration of department of medical genetics and general surgery between June 2007 and January 2010.Samples were used for genotyping for point mutations of C677T and A1298C markers for MTHFR gene. Informed consent was obtained from all of the patients and control group individuals.

\section{Mutation analysis}

Peripheric blood tissues containing EDTA from patients and control group were used for genomic DNA isolation.The total genomic DNA was extracted by the MagnaPure Compact (Roche) and Invitek kit extraction techniques (Invitek ${ }^{\circledR}$; Invisorb spin blood, Berlin, Germany). Target genes were simultaneously amplified in a biotin-labelled single multiplex amplification reaction (Viennalab ${ }^{\circledR}$; PGX-HIV StripAssay, Vienna, Austria) which is based on the reverse-hybridization principle automatically and by Real Time PCR,LightCycler 2.0 methods (Roche). The multiple polymerase chain reaction (PCR) was performed in a Perkin Elmer 9600 and the profile consisted of an initial melting step of 2 min at $94^{\circ} \mathrm{C}$; followed by 35 cycles of $30 \mathrm{~s}$ at $94^{\circ} \mathrm{C}, 30 \mathrm{~s}$ at $61^{\circ} \mathrm{C}$, and $30 \mathrm{~s}$ at $72^{\circ} \mathrm{C}$; and a final elongation step of
$7 \mathrm{~min}$ at $72^{\circ} \mathrm{C}$ for stripAssay genotyping. High portion of samples were also analysed by real-time PCR technique (LightCycler 2.0, Roche). Briefly, LightCycler FastStart DNA Master HybProbes, master mix and DNA template were used for real-time amplification.The amplification conditions for 45 cycles were; denaturation in $95^{\circ} \mathrm{C}$ for 10 seconds, annealing for 5-20 seconds, extension in $72^{\circ} \mathrm{C}$, melting curve step with denaturation in $95^{\circ} \mathrm{C}$, annealing for 30 seconds, melting in $95^{\circ} \mathrm{C}$ and cooling step in $40^{\circ} \mathrm{C}$ for 30 seconds.Software programme (LightCycler 2.0, Roche) was used for detection of the mutated and normal genotype profiles of target genes in the current CRC and healthy controls.

\section{Statistical analysis}

Alternative genotype frequencies for mutated MTHFR markers in patients of CRC and controls were compared using pearson Chi-square and multiple logistic regression analysis. Statistical analysis was performed using SPSS version 16 (SPSS, Chicago, IL, USA). A value of $\mathrm{P}<0.05$ was considered as statistically significant and mutated $\mathrm{T}$ allele frequency was discussed in the current report.

\section{Results}

Presented results show germ-line variations in MTHFR gene. Peripheral blood-EDTA samples from healthy controls and CRC patients were examined for genotyping in the current study.In a total of $86 \mathrm{CRC}$ patients [(54 male $(62.8 \%)$ and 32 female $(37.2 \%)]$ of $70(81.4 \%)$ colonal, $16(18.6 \%)$ rectal cancer mean age $63.22 \pm 30.41$ (45-87) were compared to the 212 healthy individuals from the same population (Ozdemir et al., 2012). The number of patients according to tumour type were; 72 $(83.7 \%)$ adenocarcinoma, $11(12.8 \%)$ mucinous type carcinoma, $2(2.3 \%)$ tubulovillous adenoma and $1(1.2 \%)$ glandular type tumour (Table 1). The investigated patients according to differentiated tumour types were; 38 (44.2\%) non-differentiated, $6(7.0 \%)$ poor type differentiated, $31(36.0 \%)$ intermediate type and $11(12.8 \%)$ advance tumour type (Table 1). Most of tumour were in grade 2 in the current CRC cohort histopathologically; 9 (10.5) samples were in grade 1, $54(62.8 \%)$ samples were in grade $2,8(9.3 \%)$ samples were in grade 3 and $7(8.1 \%)$ samples were in unknown profile (Table 1). Clinical inspection and histopathologic evaluation revealed that $53(61.6 \%)$ patients had lymph node metastasis, $2(2.3 \%)$ patients had bone and the rest of the patients $(28 / 32.6 \%)$ had no

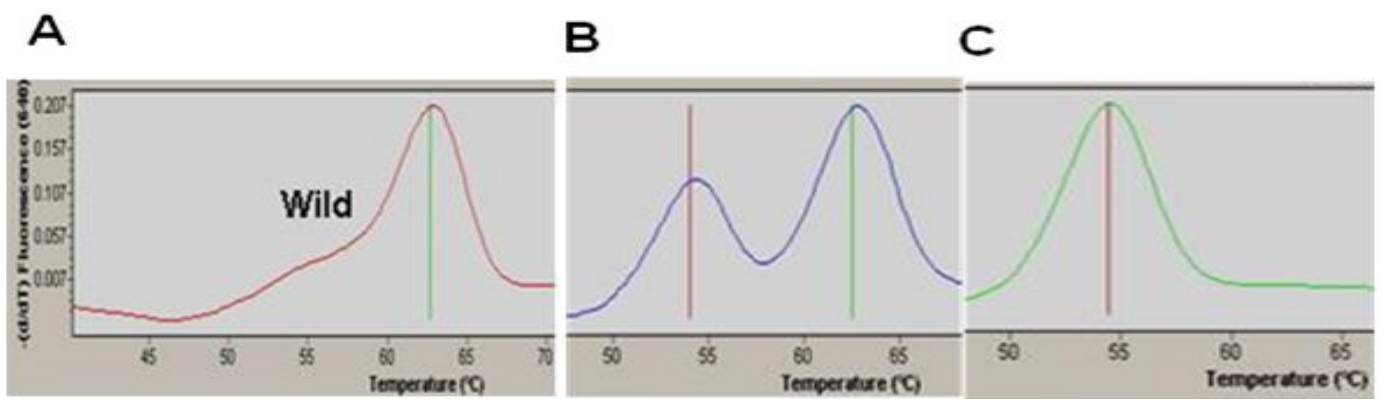

Figure 1. Real Time Melting Profiles of Wild A), Heterozygous B) and Homozygous Mutated C) MTHFR 677A>C SNP in Current CRC Tumours 
metastasis (Table 1$)$

The germ-line $\mathrm{T}$ allele frequency of $677 \mathrm{C}>\mathrm{T}$ and 1298 A $>$ C SNPs for MTHFR gene has been shown to be a risk factors for $\mathrm{CRC}$ in the current cohort from Turkish population (Figure 1), (Table 1). The distribution of genotype frequencies of the studied polymorphisms between the patients with $\mathrm{CRC}$ and control groups was in Hardy-Weinberg equilibrium. The prevalence of genotypes for MTHFR gene C677T SNP in patients with CRC $(41.9 \%$ for CC, $37.2 \%$ for CT and $20.9 \%$ for TT respectively) was higher than the control group $(73.0 \%$ for $\mathrm{CC}, 27.0 \%$ for $\mathrm{CT}$ and $0.0 \%$ for TT respectively). The prevalence of genotypes for MTHFR gene for the second SNP of $1298 \mathrm{C}$ in patients with CRC $(31.4 \%$ for AA, $54.6 \%$ for $\mathrm{AC}$ and $14.0 \%$ for CC respectively) was also higher than the control group $(34.0 \%$ for $\mathrm{AA}, 66.0 \%$ for $\mathrm{AC}$ and $0.0 \%$ for $\mathrm{CC}$ respectively), (Table 2 ). The $\mathrm{T}$ allele frequency of codon 677 SNP was 0.395 for CRC patients

Table 1. Some Clinical Characteristics Such as; the Mean age, Gender, Cancer Types of current CRC Patients from Turkish Population

\begin{tabular}{|c|c|c|c|}
\hline \multicolumn{2}{|c|}{ Clinical Characteristics } & \multicolumn{2}{|c|}{$\begin{array}{c}\text { CRC Patients (n:86) } \\
\text { No. } \%\end{array}$} \\
\hline \multicolumn{2}{|l|}{ The mean age } & \multicolumn{2}{|c|}{$63.22 \pm 30.41(45-87)$} \\
\hline \multirow[t]{2}{*}{ Gender } & M & 54 & 62.8 \\
\hline & $\mathrm{F}$ & 32 & 37.2 \\
\hline Material type & Pheripheral blood - EDTA, & 86 & 100 \\
\hline \multirow[t]{2}{*}{ Cancer type } & Rectal & 16 & 18.6 \\
\hline & Colonal & 70 & 81.4 \\
\hline \multirow[t]{4}{*}{ Tumour type } & Adenocarcinoma & 72 & 83.7 \\
\hline & Mucinous & 11 & 12.8 \\
\hline & Tubulovillous adenoma & 2 & 2.3 \\
\hline & Glandular & 1 & 1.2 \\
\hline \multirow[t]{4}{*}{ Differentiation type } & Advance & 11 & 12.8 \\
\hline & Intermediate & 31 & 36.0 \\
\hline & Poor & 6 & 7.0 \\
\hline & Non-differentiated & 38 & 44.2 \\
\hline \multirow[t]{5}{*}{ Grade } & Grade 1 & 9 & 10.5 \\
\hline & Grade 2 & 54 & 62.8 \\
\hline & Grade 3 & 8 & 9.3 \\
\hline & High Grade & 8 & 9.3 \\
\hline & Unknown & 7 & 8.1 \\
\hline \multirow[t]{4}{*}{ Metastasis } & Non-metastasis & 28 & 32.6 \\
\hline & Lymph node & 53 & 61.6 \\
\hline & Bone & 2 & 2.3 \\
\hline & Other & 3 & 3.5 \\
\hline
\end{tabular}

Table 2. The Prevalence of Genotypes and $T$ Allele Frequency of MTHFR $677 \mathrm{C}>\mathrm{T}$ and $\mathrm{C}$ Allele Frequency of MTHFR $1298 \mathrm{~A}>\mathrm{C}$ SNPs in the Current CRC Cohort and Healthy Controls

\begin{tabular}{llclrl}
\hline Gene/Genotype & & Patients (n:86) & Controls* (n:212) \\
& & No. $\%$ & No. $\%$ \\
\hline MTHFR C677T & $\mathrm{C} / \mathrm{C}$ & 36 & 41.9 & 207 & 97.6 \\
& $\mathrm{C} / \mathrm{T}$ & 32 & 37.2 & 5 & 2.4 \\
& $\mathrm{~T} / \mathrm{T}$ & 18 & 20.9 & 0 & 0.0 \\
Alleles & $\mathrm{C}$ & 104 & 0.605 & 419 & 0.988 \\
& $\mathrm{~T}^{\mathrm{a}}$ & 68 & $0.395^{* *}$ & 5 & 0.012 \\
MTHFR A1298C & $\mathrm{A} / \mathrm{A}$ & 27 & 31.4 & 209 & 98.6 \\
& $\mathrm{~A} / \mathrm{C}$ & 47 & 54.6 & 3 & 1.4 \\
Alleles & $\mathrm{C} / \mathrm{C}$ & 12 & 14.0 & 0 & 0.0 \\
& $\mathrm{~A}$ & 101 & 0.587 & 421 & 0.993 \\
& $\mathrm{C}^{\mathrm{b}}$ & 71 & $0.413^{* * *}$ & 3 & 0.007 \\
\hline
\end{tabular}

*Ozdemir et al., 2012; **The T allele was significant for MTHFR C677T; Odds Ratio $=4.2$ (2.78 6.36), $\mathrm{p}<0.0001$; ***The $\mathrm{C}$ allele was also significant for MTHFR A1298C; Odds Ratio=1.42 $(0.99-2.05)), \mathrm{p}<0.0001 ;{ }^{\mathrm{a}} \mathrm{p}$ value $<0.0001$ : Odds ratio $=4.2$ : CI $(95 \%)(2.78-6.36) ;{ }^{\mathrm{b}} \mathrm{p}$ value $<0.0001$ : Odds ratio $=1.42$ : CI $(95 \%)(0.99-2.05)$ and 0.130 for healthy individuals in the current results. MTHFR 677TT (homozygous) genotype was found $20.9 \%$ and $\mathrm{T}$ allele frequency 4.2 -fold increased in $\mathrm{CRC}$ when compared to the control group form the same ethnicity. (OR: 4.2, CI: 2.78-6.36), p<0.0001.

Similar findings were detected in the second SNP marker (A1298C) of MTHFR gene in the current CRC cohort. The $\mathrm{C}$ allele frequency of codon 1298 SNP was 0.413 for CRC patients and 0.340 for healthy individuals in the current results. MTHFR $1298 \mathrm{CC}$ (homozygous) genotype was found $14 \%$ and $\mathrm{C}$ allele frequency $1.42-$ fold increased in CRC when compared to the control group form the same ethnicity (OR: 1.42, CI: 0.99$2.05), \mathrm{p}<0.0001$.That both differences were statistically significant when compared to the control group (Table 2).

\section{Discussion}

Most of the CRC cases are sporadic but approximately $25 \%$ of patients have a familial history. Multiple ethiological parameters such as; genetic variation, epigenetics, socioeconomic, demographic, racial and ethnic diversity impacts on outcomes of disease and must be carefully considered in CRC evaluation (Kono et al., 2005; Cheah et al., 2009). However, the exact molecular trigger mechanisms of CRC has not been completely defined yet. The systemic functional gene MTHFR is a one of the trigger molecule in human complex diseases including CRC (Ge et al., 2012). Gene has pluripotent affect on folate metabolism, cells methyl sources, gene regulation, DNA methylation, maintain the integrity and stability of DNA (Ge et al., 2012). Literature findings show conflicting results about MTHFR role in oncogenesis. In several studies, the 677TT genotype was associated with an increased risk of CRC (Gallegos - Arreola et al., 2009; Sameer et al., 2011). Guerreiro et al. (2008) have found that the TT genotype is associated with an increased risk for CRC in Portuguese population but no relationship was reported in district region of Turkish population (Zeybek et al., 2007). The results about MTHFR A1298C SNP on CRC risk are also conflict (Chang et al., 2007; Zeybek et al., 2007; Cao et al., 2008). For the 1298 CC genotype, two studies reported an increase in risk (Kury et al., 2008; Lightfoot et al., 2008), while other some meta-analyses suggest that $1298 \mathrm{CC}$ genotypes may be associated with a decrease in CRC risk (Huang et al., 2007; Fernandez-Peralta et al., 2010; Li et al. 2011) in Chinese Han population. Nassiri et al (2013) have claimed that the SNPs in MTHFR gene that associated with colorectal cancer can be used as a potential genetic marker tool for improving cancer diagnosis and treatment. Yousef et al (2013) have also claimed that the 677 SNP and the TA haplotype of MTHFR gene may modulate the risk for CRC development among the Jordanian population. But, lower risk were reported for MTHFR 677T allele in Asian (Yang et al., 2013) and Spanish populations (Huang et al., 2007).

In the current study similar findings were detected in the second SNP marker (A1298C) of MTHFR gene in the current $\mathrm{CRC}$ cohort. The germ-line $\mathrm{T}$ allele for codon $677 \mathrm{C}>\mathrm{T}$ and $\mathrm{C}$ allele frequencies of codon $1298 \mathrm{~A}>\mathrm{C}$ SNPs has been shown to be a risk factors for CRC in the 
current cohort from Turkish population. The prevalence of genotypes for MTHFR gene C677T SNP in patients with CRC (41.9\% for CC, $37.2 \%$ for CT and $20.9 \%$ for TT respectively) was higher than the control group The T allele frequency of codon 677 SNP was 0.395 for CRC patients and 0.130 for healthy individuals in the current results. MTHFR 677TT (homozygous) genotype was found $20.9 \%$ and $\mathrm{T}$ allele frequency 4 .2-fold increased in $\mathrm{CRC}$ when compared to the control group form the same ethnicity. (OR: 4.2, CI: 2.78-6.36), p<0.0001.

The C allele frequency of codon 1298 SNP was 0.413 for CRC patients and 0.340 for healthy individuals in the current results. MTHFR 1298CC (homozygous) genotype was found $14 \%$ and $\mathrm{C}$ allele frequency 1.42 -fold increased in CRC when compared to the control group form the same ethnicity (OR: 1.42, CI: 0.99-2.05), $\mathrm{p}<0.0001$.That both differences were statistically significant when compared to the control group (Table 2). Some of the previous studies demonstrate that notable difference between patients and controls whereas remaining studies found that there was no association for both of polymorphisms. The different results regarding the effects of those genetic polymorphisms on CRC risk can be ascribed to the differences in racial origin of the population, the lifestyle, and the pattern of diet in distinct countries (Zhao et al., 2014). Recent literature findings reflect an importance of genes involved in folate metabolism in complicated diseases and cancer risk by pleiotropic effect (Yousef et al., 2013; Ozdemir et al., 2014). Torre at al. (2014) have claimed that polymorphic 677TT MTHFR SNP with other conditions such as; smoke, high HbA1c levels and dyslipidaemia are increased colorectal tumour risk. Here we report increased germ-line mutation profiles in both polymorphic MTHFR gene SNPs in CRC patients in Turkish population.

It is well known that, many parameters such as; oncogenes, epigenetic alterations in tumour suppressor genes, viruses and many other intrinsic and/or extrinsic environmental factors may directly play crucial role in CRC progression. The current results with some of previous literature findings have pointed out the importance of the functional gene mediated CRC progression. Presented results show germ-line variations in MTHFR gene that the homozygous individuals for MTHFR 677TT and 1298CC SNPs are more likely to develop CRC than those with wild-type genotype.

In conclusion, current results indicates susceptibility of germ-line C677T and A1298C SNPs in systemic functional gene of MTHFR that associated with CRC risk in Turkish population. It is also possible to assumed that parents with mutated for both SNPs may contribute CRC risk in their offsprings by germ-lime mutated allele inheritance.

\section{References}

Blount BC, Mack MM, Wehr CM, et al (1997). Folate deficiency causes uracil misincorporation into human DNA and chromosome breakage: implications for cancer and neuronal damage. Proc Natl Acad Sci USA, 94, 3290-5.

CaoHX, Gao CM, Takezaki T, et al (2008) Genetic polymorphisms of methylenetetrahydrofolate reductase and susceptibility to colorectal cancer. Asian Pac J Cancer Prev, 9, 203-8.

Chang SC, Lin PC, Lin JK, et al (2007). Role of MTHFR polymorphisms and folate levels in different phenotypes of sporadic colorectal cancers. Int J Colorectal Dis, 22, 483-9.

Cheah PY(2009). Recent advances in colorectal cancer genetics and diagnostics. Crit Rev Oncol Hematol, 69, 45-55.

Chen J, Ma J, Stampfer MJ, et al (2002). Linkage disequilibrium between the $677 \mathrm{C}>\mathrm{T}$ and $1298 \mathrm{~A}>\mathrm{C}$ polymorphisms in human methylenetetrahydrofolate reductase gene and their contributions to risk of colorectal cancer. Pharmacogenetics, 12,339-42.

Choi SW, Mason JB (2000). Folate and carcinogenesis: an integrated scheme. J Nutr, 130, 129 -32.

de Kok TM, van Maanen JM (2000). Evaluation of fecal mutagenicity and colorectal cancer risk. Mutat Res, $\mathbf{4 6 3}$, 53-101.

Deloughery TG, Evans A, Sadeghi A, et al (1996). Common mutation in methylenetetrahydrofolate reductase. Correlation with homocysteine metabolism and late-onset vascular disease. Circulation, 94, 3074-8.

Fang JY, Xiao SD (2003). Folic acid, polymorphism of methylgroup metabolism genes, and DNA methylation in relation to GI carcinogenesis. J Gastroenterol, 38, 821-9.

Fearon ER, Vogelstein BA (1990). Genetic model for colorectal tumorigenesis. Cell, 61, 759-67.

Fernandez-Peralta AM, Daimiel L, Nejda N, et al (2010). Association of polymorphisms MTHFR C677T and A1298C with risk of colorectal cancer, genetic and epigenetic characteristic of tumors, and response to chemotherapy. Int J Colorectal Dis, 25, 141-51.

Friedman G,Goldschmidt N,Friedlander Y,et al(1999).Acommon mutation A1298C in human methylenetetrahydrofolate reductase gene: association with plasma total homocysteine and folate concentrations. $J$ Nutr, 129, 1656-61.

Frosst P, Blom HJ, Milos R, et al (1995). Candidate genetic risk factor for vascular disease: a common mutation in methylenetetrahydrofolate reductase [letter]. Nat Genet, 10, 111-3.

Gallegos-Arreola MP, García-Ortız JE, Figuera LE, et al (2009). Association of the $677 \mathrm{C}>\mathrm{T}$ polymorphism in the MTHFR gene with colorectal cancer in Mexican patients. Cancer Genomics Proteomics, 6, 183-8.

Ge H, Zheng X, Zhao E, et al (2012). Letter to the editor: a meta-analysis of association between polymorphism of MTHFR A1298C and colorectal cancer risk. Int J Colorectal Dis, 27, 1387-8.

Goyette P, Aditya P, Renate M, et al (1998). Gene structure of human and mouse methylenetetrahydrofolate reductase (MTHFR). Mammalian Genome, 9, 652-6.

Guerreiro CS, Carmona B, Gonçalves S, et al (2008). Risk of colorectal cancer associated with the $\mathrm{C} 677 \mathrm{~T}$ polymorphism in 5,10-methylenetetrahydrofolate reductase in Portuguese patients depends on the intake of methyl-donor nutrients. American Society for Nutrition, Am J Clin Nutr, 88, 1413-8.

Huang Y, Han S, Li Y, et al (2007). Different roles of MTHFR C677T and A1298C polymorphisms in colorectal adenoma and colorectal cancer: a meta-analysis. J Hum Genet, 52, 73-85.

Izmirli M, Inandiklioglu N, Abat D, et al (2011). MTHFR gene polymorphisms in bladder cancer in the Turkish population. Asian Pac J Cancer Prev, 12,1833-35.

Izmirli M (2013). A literature review of MTHFR (C677T and A1298C polymorphisms) and cancer risk. Mol Biol Rep, 40, 625-37.

Kono S, Chen K (2005). Genetic polymorphisms of methylenetetrahydrofolate reductase and colorectal cancer 
and adenoma. Cancer Science, 96, 535-42.

Kury S, Buecher B, Robiou-du-Pont S, et al (2008). Lowpenetrance alleles predisposing to sporadic colorectal cancers: a French case-controlled genetic association study. BMC Cancer, $8,326$.

Li H, Xu WL, Shen HL, et al (2011). Methylenetetrahydrofolate reductase genotypes and haplotypes associated with susceptibility to colorectal cancer in an eastern Chinese Han population. Genet Mol Res, 10, 3738-46.

Lightfoot TJ, Barrett JH, Bishop T, et al (2008). Methylene tetrahydrofolate reductase genotype modifies the chemopreventive effect of folate in colorectal adenoma, but not colorectal cancer. Cancer Epidemiol Biomarkers Prev, 17, 2421-30.

Nassiri M, Kooshyar MM, Roudbar Z, et al (2013). Genes and SNPs associated with non-hereditary and hereditary colorectal cancer. Asian Pac J Cancer Prev, 14, 5609-14.

Ozdemir O, Yenicesu GI, Silan F, et al (2012). Recurrent Pregnancy Loss and Its Relation to Combined Parental Thrombophilic Gene Mutations. Genet Test Mol Biomarkers, 16, 279-86.

Ozdemir O, Silan F, Urfali M, et al (2014). Variable R.Msp1 fragmentation in genomic DNA due to DNA hypomethylation in CRF patients with MTHFR C677Tgene polymorphism: from genetics to epigenetics. Genet Test Mol Biomarkers, 6, 77-87.

Pardini B, Kumar R, Naccarati A, et al (2011). MTHFR and MTRR genotype and haplotype analysis and colorectal cancer susceptibility in a case-control study from the Czech Republic. Mutat Res, 721, 74-80.

Parkin DM, Bray F, Ferlay J, et al (2002). Global cancer statistics. CA Cancer J Clin, 55, 74-108.

Parle-McDermott A, Mills JL, Molloy AM, et al (2006). The MTHFR 1298CC and 677TT genotypes have opposite associations with red cell folate levels. Mol Genet Metab, 88, 290-4.

Sameer AS, Shah ZA, Nissar S, et al (2011). Risk of colorectal cancer associated with the methylenetetrahydrofolate reductase (MTHFR) C677T polymorphism in the Kashmiri population. Genet Mol Res, 10, 1200-10.

Schwartz SM, Siscovick DS, Malinow MR, et al (1997). Myocardial infarction in young women in relation to plasma total homocysteine, folate, and a common variant in the methylenetetrahydrofolate reductase gene. Circulation, 96, 412-7.

Slattery ML, Potter JD, Samowitz W, et al (1999). Methylenetetrahydrofolate reductase, diet, and risk of colon cancer. Cancer Epidemiol Biomarkers Prev, 8, 513-8.

Stern LL, Mason JB, Selhub J, et al (2000). Genomic DNA hypomethylation, a characteristic of most cancers, is present in peripheral leukocytes of individuals who are homozygous for the C677T polymorphism in the methylenetetrahydrofolate reductase gene. Cancer Epidemiol Biomarkers Prev, 9, 849-53.

Torre ML, Russo GT, Ragonese M, et al (2014). MTHFR C677T polymorphism, folate status and colon cancer risk in acromegalic patients. Pituitary, 17, 257-66.

Ulrich CM, Bigler J, Bostick R, et al (2002). Thymidylate synthase promoter polymorphism, interaction with folate intake, and risk of colorectal adenomas. Cancer Res, 62 , 3361-4.

van der Put NM, Gabreels F, Stevens EM, et al (1998). A second common mutation in the methylenetetrahydrofolate reductase gene: an additional risk factor for neural-tube defects? Am J Hum Genet, 62, 1044-51.

Weisberg I, Tran P, Christensen B, et al (1998). Second genetic polymorphism in methylenetetrahydrofolate reductase
(MTHFR) associated with decreased enzyme activity. Mol Genet Metab, 64, 169-72.

Weisberg IS, Jacques PF, Selhub J, et al (2002). The 1298A > $\mathrm{C}$ polymorphism in methylenetetrahydrofolate reductase (MTHFR): in vitro expression and association with homocysteine. Atherosclerosis, 156, 409-15.

Xu XL, Yu J, Zhang HY, et al (2004). Methylation profile of the promoter $\mathrm{CpG}$ islands of 31 genes that may contribute to colorectal carcinogenesis. World J Gastroenterol, 10, 3441-54

Yang Z, Zhang XF, Liu HX, et al (2012). MTHFR C677T Polymorphism and colorectal cancer risk in Asians, a meta-analysis of 21 studies. Asian Pacific J Cancer Prev, 13, 1203-8.

Yousef AM, Shomaf M, Sondra Berger S, et al (2013). Allele and genotype frequencies of the polymorphic methylenetetrahydrofolate reductase and colorectal cancer among Jordanian population. Asian Pac J Cancer Prev, 14, 4559-65.

Zeybek U, Yaylim I, Yilmaz H, et al (2007). Methylenetetrahydrofolate reductase C677T polymorphism in patients with gastric and colorectal cancer. Cell Biochem Funct, 25, 419-22.

Zhao J, Li W, Zhu D, et al (2014).Association of single nucleotide polymorphisms in MTHFR and ABCG2 with the different efficacy of first-line chemotherapy in metastatic colorectal cancer. Med Oncol, 31, 802. 